ARTICLE

\title{
Extinction of eastern Sahul megafauna coincides with sustained environmental deterioration
}

\author{
Scott A. Hocknull (10) ${ }^{1,2}$, Richard Lewis (10 ${ }^{3}$, Lee J. Arnold ${ }^{3}$, Tim Pietsch ${ }^{4}$, Renaud Joannes-Boyau (i) ${ }^{5}$, \\ Gilbert J. Price (1) ${ }^{6}$, Patrick Moss (1) ${ }^{6}$, Rachel Wood ${ }^{7,8}$, Anthony Dosseto (1) ${ }^{9}$, Julien Louys (1) ${ }^{10}$, Jon Olley ${ }^{4} \&$ \\ Rochelle A. Lawrence (iD ${ }^{1}$
}

Explanations for the Upper Pleistocene extinction of megafauna from Sahul (Australia and New Guinea) remain unresolved. Extinction hypotheses have advanced climate or humandriven scenarios, in spite of over three quarters of Sahul lacking reliable biogeographic or chronologic data. Here we present new megafauna from north-eastern Australia that suffered extinction sometime after 40,100 ( \pm 1700 ) years ago. Megafauna fossils preserved alongside leaves, seeds, pollen and insects, indicate a sclerophyllous forest with heathy understorey that was home to aquatic and terrestrial carnivorous reptiles and megaherbivores, including the world's largest kangaroo. Megafauna species diversity is greater compared to southern sites of similar age, which is contrary to expectations if extinctions followed proposed migration routes for people across Sahul. Our results do not support rapid or synchronous human-mediated continental-wide extinction, or the proposed timing of peak extinction events. Instead, megafauna extinctions coincide with regionally staggered spatio-temporal deterioration in hydroclimate coupled with sustained environmental change.

\footnotetext{
${ }^{1}$ Geosciences, Queensland Museum, 122 Gerler Rd., Hendra, QLD 4011, Australia. ${ }^{2}$ School of BioSciences, Faculty of Science, University of Melbourne, Melbourne, VIC 3010, Australia. ${ }^{3}$ School of Physical Sciences, Environment Institute, and Institute for Photonics and Advanced Sensing (IPAS), University of Adelaide, North Terrace Campus, Adelaide, SA 5005, Australia. ${ }^{4}$ Australian Rivers Institute, Griffith University, Brisbane, QLD 4122, Australia.

${ }^{5}$ Geoarchaeology and Archaeometry Research Group, Southern Cross GeoScience, Southern Cross University, Lismore, NSW 2480, Australia. ${ }^{6}$ School of Earth and Environmental Sciences, The University of Queensland, Brisbane, QLD 4072, Australia. ${ }^{7}$ Radiocarbon Facility, Research School of Earth Sciences, Australian National University, Building 142 Mills Road, Canberra, ACT 2601, Australia. ${ }^{8}$ School of Archaeology and Anthropology, Australian National University, Building 44, Daley Road, Canberra, ACT 2601, Australia. ${ }^{9}$ Wollongong Isotope Geochronology Laboratory, School of Earth, Atmospheric and Life Sciences, University of Wollongong, Wollongong, NSW 2522, Australia. ${ }^{10}$ Australian Research Centre for Human Evolution, Environmental Futures Research Institute, Griffith University, Mount Gravatt, QLD 4122, Australia. ${ }^{凶}$ email: scott.hocknull@qm.qld.gov.au
} 
T he Pleistocene megafauna of Sahul are defined here as nonmarine vertebrates that exceed a mass of $\sim 40-44 \mathrm{~kg}^{1}$, comprising giant species of birds, reptiles and marsupials. They have vastly different phylogenetic histories ${ }^{2}$, occupying a diverse range of habitats ${ }^{3-5}$ and reaching maximal body size by the Upper Pleistocene $e^{6-8}(126,000-11,700$ years ago (ka)). In the context of this work we do not consider unusually large-bodied taxa with a mass $<40 \mathrm{~kg}$ as megafauna, but acknowledge that many species $<40 \mathrm{~kg}$ also suffered extinction during the Pleistocene ${ }^{9,10}$. Some megafauna species were widely distributed across Sahul during the Quaternary, such as the giant wombatlike Diprotodon optatum ${ }^{7}$; however, data on the biochronology and palaeobiogeography of most species remains poor and patchy ${ }^{9,10}$.

The megafauna fossil record of Sahul worsens when only those vertebrate fossil sites considered to be reliably-dated are considered $^{11}$. Thus assessing extinction chronologies using the presently available vertebrate fossil record is hampered by few reliably-dated Upper Pleistocene sites within Marine Isotope Stage 3 (MIS 3) (57-29 ka). This period of time is particularly important because it occurs at a time controversially proposed to encompass the complete continental-wide extinction of megafauna ${ }^{12,13}$ with the peak of extinction events occurring around $42.1 \mathrm{ka}^{10,14}$.

To augment this poor record, dung fungal spores (Sporormiella) recovered from lake and marine sediments have been used as a proxy of megafauna presence and abundance with reduced spore counts interpreted as indicating megafauna decline and extinction ${ }^{15,16}$. However the validity of fungal spores as useful proxies for megafauna requires cautious interpretation due to the numerous factors impacting their dispersal and survival into the fossil record, including taphonomic, sedimentological and biological considerations ${ }^{17,18}$. Without a clear link between Sahul megafauna and these dung fungi its utility as a robust proxy is equivocal ${ }^{10,19}$.

Current explanations for megafauna extinction are therefore based on a significant spatio-temporal gap in the vertebrate fossil record, which approximates three quarters of the area of the Sahul continent (Fig. 1e). This problem is most evident for central and northern Australia, and New Guinea, where no reliably-dated megafauna occur within MIS 3. This conspicuous gap has not restricted the development of generalised and polarised interpretations to explain the continental-wide extinction of the megafauna, with the prevailing extinction scenarios advancing climate change $e^{9,20}$ or anthropogenic ${ }^{12,14,21,22}$ factors.

The discovery of fossil bones by Barada Barna Traditional Owners at South Walker Creek (SWC), Queensland Museum Locality (QML) 1470, near the township of Nebo, north-eastern Australia, resulted in systematic excavation of new fossil deposits that recovered Pleistocene megafauna. These sites are located in tropical Australia at the northern-most portion of the Fitzroy River Basin (FRB), an east-draining catchment that exits south onto the southern Great Barrier Reef, near Rockhampton, centraleastern Queensland (Fig. 1). Importantly, the FRB is located within the 'data gap' for megafauna and adjoins Australia's two largest basins to the west. Both of these basins, the inlanddraining Lake Eyre Basin (LEB) and the south-draining MurrayDarling Basin (MDB), have reliably-dated megafauna sites and possess established palaeoenvironmental proxies ${ }^{20,23-28}$.

Here we present a new and diverse Pleistocene megafaunal assemblage unique to eastern Sahul. We then provide a chronology for these megafauna that combine observations of site geology and taphonomy with a chronometric dating assessment. Reliable numerical ages are reported for four megafauna sites using multiple dating techniques and applied quality rating criteria $^{11}$. These results are then integrated into the established regional and local palaeoenvironmental and archaeological records that provide important context for testing the prevailing megafauna extinction hypotheses for Sahul. Our results do not support rapid or synchronous human-mediated continental-wide extinction or the proposed timing of peak extinctions around $42.1 \mathrm{ka}$. Instead, megafauna extinctions coincide with regionally staggered spatio-temporal deterioration in hydroclimate coupled with locally sustained environmental changes that were arguably detrimental to megafauna survival.

\section{Results}

New and diverse tropical megafauna. Four sites along a stretch of Walker Creek represent the South Walker Creek fossil deposits reported here that contain the remains of a new and diverse megafauna assemblage (Fig. 2). Fossil fauna and flora are taxonomically identified along with descriptions of these remains (Supplementary Notes 1-3), their taphonomic, depositional and stratigraphic context (Supplementary Notes $2 \& 4$ ). The deposits preserve body and trace fossils from small to megafauna-sized vertebrates, aquatic and terrestrial invertebrates (e.g. bivalves and insects) and floral remains (e.g. seeds, leaves and pollen) (Fig. 2a, f-x, Supplementary Figs. 1-7 \& 10).

The combination of fauna and flora preserved within an open fossil site in Australia is rare. Recently, modelled suitability ratings for preservation and discoverability of megafauna fossils rates the SWC area at, or close to, zero ${ }^{29}$. This suggests that either these fossil deposits are truly exceptional or the models require further refinement before being considered useful. The SWC sites thus offer a rare opportunity to develop a holistic account of megafauna within a tropical northern palaeoenvironment from northern Australia and eastern Sahul.

At least sixteen megafauna species are present, including thirteen extinct and three extant species. Carnivorous megafauna are represented by the marsupial 'lion', Thylacoleo, at least three crocodilians (Crocodylus sp. cf. C. porosus, Pallimnarchus sp. and 'Quinkana' sp.) and two giant monitor lizards (Varanus priscus ("Megalania") and a Komodo Dragon-sized species). Mega- and Macroherbivores are diverse with five species of kangaroo, two wombats, one palorchestid, two diprotodontids and the emu, Dromaius sp. cf. D. novaehollandiae (Table 1, Supplementary Note 1).

The macropodids are morphologically distinct taxa but remain largely enigmatic due to low numbers of preserved dental remains and uncertain species-level taxonomies (Supplementary Note 1 and Supplementary Fig. 5). Five species of macropodine, including a species each of Macropus, Notamacropus, Osphranter and Protemnodon, as well as a species of small-sized sthenurine, define a kangaroo fauna that bears little resemblance to the 'typical' Upper Pleistocene sthenurine-dominated kangaroo faunas of southern Australia 6,30 . Also, macropodines that are commonly documented from Pleistocene open sites in the bordering MDB catchment to the south of the FRB; such as Macropus giganteus titan, Macropus ferragus, Notamacropus agilis siva and Protemnodon anak ${ }^{31}$, are notably absent from the SWC macropodid fauna. These taxa are of similar body size to those found at SWC; therefore, it is unlikely that these faunal absences are due to taphonomic sampling bias.

The SWC macropodines are all high crowned forms, including the species of Protemnodon, which is either a new species or a northern variant of the similar-sized Protemnodon brehus (Supplementary Note 1; Supplementary Fig. 5, ab-an). The largest and most common macropodine is possibly a new species of Macropus that possesses a combination of characteristics found in Pliocene-aged Macropus pan and Pleistocene-aged Macropus pearsoni. Comparison of limb dimensions of this giant species to 


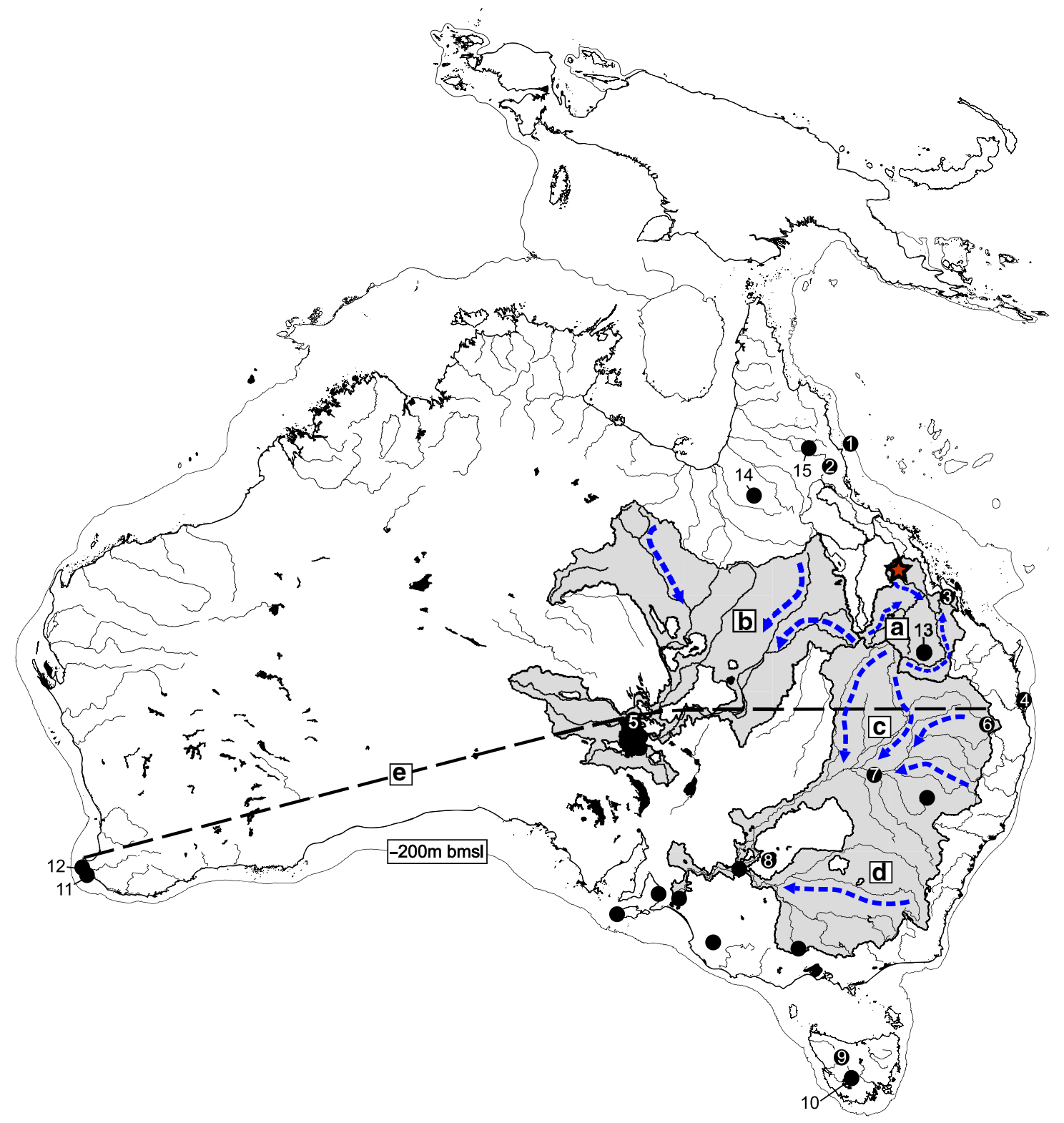

Fig. 1 Map of Sahul (Australia and New Guinea) showing the distribution of reliably-dated megafauna sites within MIS 3 (57-29 ka) and locations mentioned in the text. Red star indicates South Walker Creek. a The Fitzroy River Basin (FRB). b The Lake Eyre Basin (LEB). c The northern Darling and d southern Murray River catchments of the Murray-Darling Basin (MDB). e Over three quarters of the continental area of Sahul is missing reliably-dated sites from MIS 3, here indicated north of the dashed line. Other localities mentioned in text, 1. ODP 820, 2. Lynch's Crater, 3. Capricorn Caves, 4. North Stradbroke Island, 5. Kati Thanda-Lake Eyre, 6. Ned's Gully, 7. Cuddie Springs, 8. Lake Mungo, 9. Mt. Cripps, 10. Titan's Shelter, 11. Tight Entrance Cave, 12. Kudjal Yolgah Cave, 13. Kenniff Cave, 14. Gledswood Shelter and 15. Ngarrabullgan. Blue arrows indicate catchment flow direction. bmsl $=$ below mean present day sea level indicating outline of the Sahul continent. The baseline map was generated in QGIS using shoreline data from https://www.ngdc.noaa. gov/mgg/shorelines/ under GNU Lesser General Public License v3 or later; and drainage basin data 111 from https://data.gov.au/data/dataset/f55ec9b3ab74-4056-93a2-b4b8aa65ead1 under Creative Commons Attribution 4.0 International; and bathymetry data112 from https://data.gov.au/data/dataset/ australian-bathymetry-and-topography-grid-june-2009 under Creative Commons Attribution 4.0 International. The base map was composited using Corel Draw and altered to delineate 'Lake Carpentaria'.

those of other giant macropodid skeletons indicates that this taxon is the largest species of kangaroo. Maximum tibial length is at least $250 \mathrm{~mm}$ longer than that of the largest known specimens of Procoptodon goliah, Macropus giganteus titan, and Macropus ferragus $^{32}$ (Supplementary Note 1; Supplementary Figs. $4 \& 5$, 1aa). Based on femoral circumference, mass is estimated at around $274 \mathrm{~kg}, \sim 43 \mathrm{~kg}$ heavier than the second largest species, the sthenurine Procoptodon goliah $^{33}$ (Supplementary Note 3). A species of Notamacropus is distinguishable from $N$. agilis siva, thus likely a new species or another northern variant
(Supplementary Note 1; Supplementary Fig. 5a-i). A species of Osphranter is morphologically indistinguishable from very large individuals of the extant Red Kangaroo (Osphranter rufus) (Supplementary Note 1; Supplementary Fig. 5j). Together, the dominance of new macropodid forms along with the absence of common and widely distributed species indicates that the Pleistocene palaeoenvironment at SWC is presently unique in Sahul.

A species of Palorchestes is morphologically similar to P. azael but much smaller and is distinguishable from species similar in 

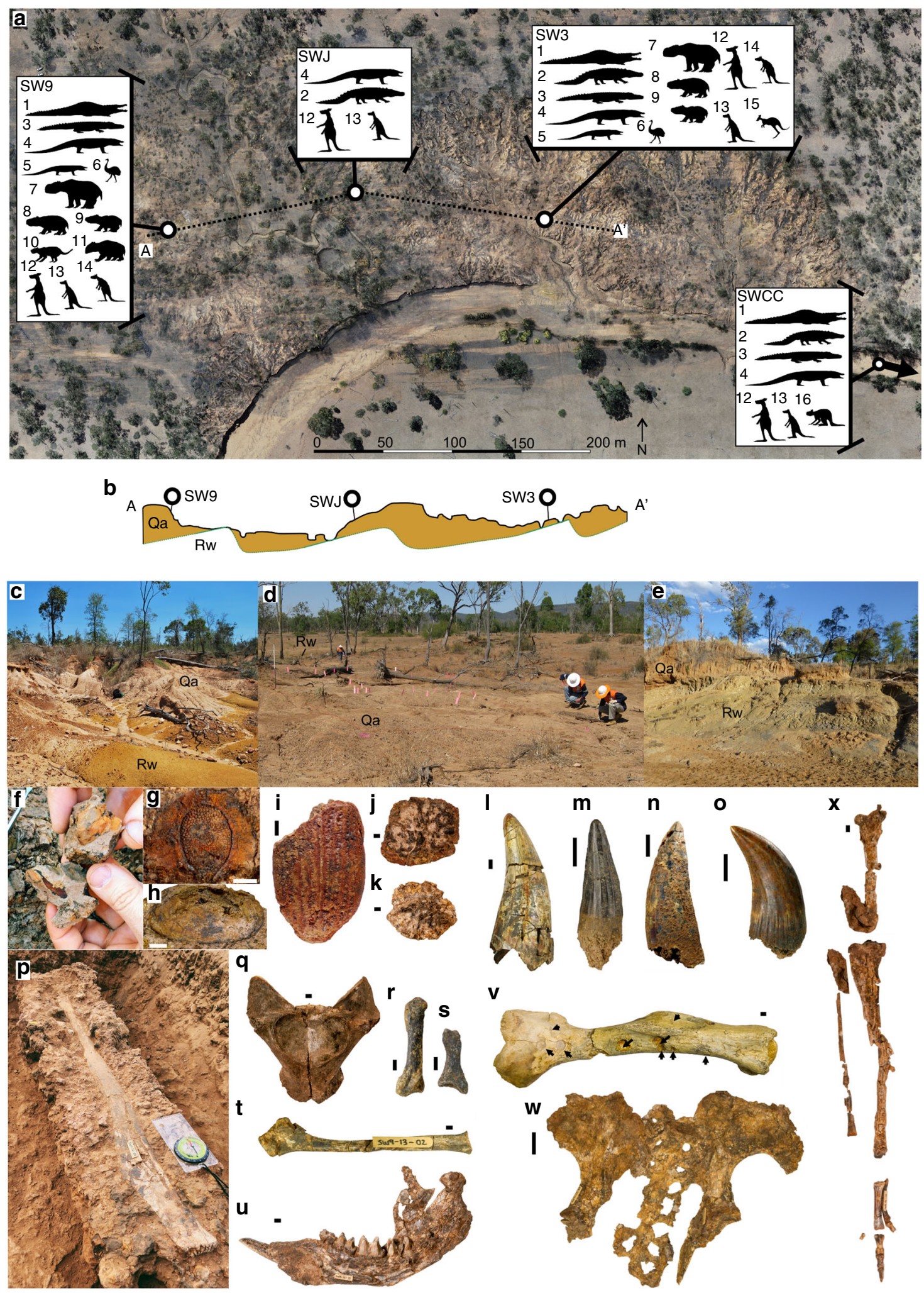

size (e.g. P. parvus) (Supplementary Note 1; Supplementary Fig. $6 \mathrm{a}-\mathrm{c})$. This species may represent either a new species or another northern variant. The remaining megafauna are referrable to known taxa, including Diprotodon optatum, Zygomaturus trilobus, Phascolonus gigas and Sedophascolomys sp. cf. S. medius (Supplementary Note 1; Supplementary Figs. 6 \& 7). The specimens of SWC Diprotodon optatum are within the smallest size range when compared with those of Pleistocene sites from the MDB and $\mathrm{LEB}^{7,34}$ (Supplementary Table 2).

Reliable megafauna ages for eastern Sahul. The four SWC sites presented here were assessed geologically, taphonomically and chronometrically so that the new fauna could be placed within a 
Fig. 2 Summary of field sites and diversity of fossil remains from South Walker Creek (QML1420). a Aerial map of main South Walker Creek fossil sites SW9, SWJ and SW3 with downstream site SWCC indicated by arrow. Megafauna taxa recovered from each site indicated by numbered silhouette: 1. Pallimnarchus sp. 2. 'Quinkana' sp., 3. Crocodylus sp. cf. C. porosus, 4. Varanus priscus, 5. Varanus sp. (large), 6. Dromaius sp., 7. Diprotodon optatum, 8. Phascolonus gigas, 9. Sedophascolomys sp. cf. S. medius, 10. Thylacoleo sp., 11. Palorchestes sp., 12. Macropus sp. (giant), 13. Protemnodon sp., 14. Notamacropus sp. (giant), 15. Osphranter sp. cf. O. rufus, 16. sthenurine. b Stratigraphic section A-A' crossing through SW9, SWJ and SW3 (indicated by dashed line in (a)). Quaternary (Qa) alluvial sediment overlies dipping basement Permo-Triassic Rewan Group (Rw) bedrock (vertical exaggeration $5 \times$ ). Fossil deposit surface expression at SW9 (c), SW3 (d) and SWCC (e). Summary of the diverse fossil remains recovered from SWC sites (see Supplementary Note 1 for detailed descriptions): $\mathbf{f}$ leaves and bivalves in situ at SW9; $\mathbf{g}$ Goodeniaceae seed; $\mathbf{h}$ Velesunio wilsoni bivalve; i insect elytron (?Curculionidae); $\mathbf{j}$ Pallimnarchus sp. osteoderm; k Crocodylus sp. cf. C. porosus osteoderm; isolated crocodile teeth from I Pallimnarchus, $\mathbf{m}$ Crocodylus sp. and $\mathbf{n}$ 'Quinkana'; - Varanus priscus tooth; p Macropus sp. (giant) tibia in situ at SW9; q Varanus priscus dorsal vertebra; associated appendicular elements from Thylacoleo sp., $\mathbf{r}$ metacarpal, s phalange and $\mathbf{t}$ fibula; $\mathbf{u}$ Diprotodon optatum right dentary; v Macropus sp. (giant) humerus with crocodile puncture marks (indicated by arrows); w Articulated pelvis and caudal vertebrae of Phascolonus gigas from SW9; $\mathbf{x}$ associated hind limb of juvenile Protemnodon sp. from SW9. Scale bars equal $1 \mathrm{~mm}$ in $(\mathbf{g}, \mathbf{i}) ; 5 \mathrm{~mm}$ in (h, $\mathbf{j}-\mathbf{t}, \mathbf{v}, \mathbf{x}) ; 10 \mathrm{~mm}$ in (u); and $50 \mathrm{~mm}$ in $(\mathbf{w})$.

reliable chronology. The detailed results of these assessments are provided in Supplementary Notes 3-8. All of the sites occur within Quaternary alluvial deposits accumulated atop shallowdipping Permo-Triassic bedrock. Each deposit represents a different sedimentary accumulation ranging from small-scale rapid burial events to larger-scale accretionary deposits (Fig. 2a-e; Supplementary Note 4; Supplementary Figs. 11-14 and Supplementary Tables 4-7). Although common, large channel-fill deposits are consistently unfossiliferous.

Taphonomic and sedimentological evidence indicates a primary depositional context for the fossils with no evidence of secondary reworking other than present day exposure and erosion. Taphonomic characteristics of the vertebrate remains range from direct bone modification made by predators (e.g. crocodiles (Fig. 2v) and Thylacoleo sp. bite marks (Supplementary Fig. 10d)) to dry and wet bone fractures dominated by weathering stage 0 , indicating short-term exposure ${ }^{35}$ (Supplementary Note 4; Supplementary Fig. 9). Voorhies Groups I, II and III are observed in combination at most sites and each site preserves different degrees of skeletal association ranging from articulated to isolated elements indicating varying levels of transport ${ }^{36}$ (Fig. 2w; Supplementary Note $2 \&$ 4; Supplementary Figs. 5, 6, 9, 10 and Supplementary Table 3 ). We acknowledge the complex taphonomic processes at play within fluvial systems ${ }^{37}$; however, the presence of articulated and associated remains with limited predepositional weathering at two sites in particular (QML1470 (SW9) and QML1470 (SW3)) demonstrates low levels of transport prior to burial (Fig. $2 \mathrm{w}$; Supplementary Note $2 \& 4$ ). The preservation of delicate remains, such as insect and seed parts, further supports rapid deposition at SW9 (Fig. 2f-I; Supplementary Fig. 1). Post-depositional alterations of the fossils (e.g. bones, teeth, leaves, seeds, molluscs and insects) are localised at each site and include iron-oxide and carbonate precipitation, cortical bone and tooth enamel splitting, microscopic surface bone striations and bone deformation (Supplementary Fig. 10). Taphonomic characteristics developed for vertebrates ${ }^{38}$ form the basis for our interpretation, including subsurface alterations via long-term drying and compaction of the mud-dominated host matrix (Supplementary Note 4). Post-depositional introduction of younger sediment is only observed within the north-east portion at one site (SW9) as sediment-filled cracks. This indicates postdepositional drying of the deposit and introduction of younger sediment into these cracks, which were avoided or sampled separately during sampling for optically stimulated luminescence (OSL) (Supplementary Figs. 11 \& 15). Sediment-filled cracks were not observed anywhere else within SW9, or at any other site.

No evidence has been found to indicate reworking of older faunal remains into deposits at SW9, which is independently supported by uranium-series (U-series) assessments of fossilised teeth from SW9 (Supplementary Note 7). Six megafauna species from SW9 were directly dated using U-series laser ablation and micro-profiling, all returning consistent and younger ages than other techniques, therefore, supporting the primary context of the deposit through the absence of reworked older fossils (Table 2, Supplementary Note 7). Together, this gives us confidence that the chronometric assessment of the fossils and sediments entraining them accurately reflect the depositional age of the fossils.

To chronometrically constrain the age of the megafauna sites we used multiple dating techniques to age the fossils or the sediment they were buried in. Direct dating of fossils is considered the most reliable approach for establishing extinction chronologies with a quality rating of $\mathrm{A}^{*}$ or $\mathrm{A}^{11}$, therefore, we applied radiocarbon, U-series, and $\mathrm{U}$-series combined with electron spin resonance (ESR) techniques to fossilised megafauna teeth and bones from the best preserved and most fossiliferous site, SW9. U-series and U-series-ESR techniques provided viable results (Table 2, Supplementary Notes $7 \& 8$ ); however, radiocarbon assessment of megafauna bones was unsuccessful due to a lack of collagen (Supplementary Note 6).

Dating of sediments derived from above, within, and below the fossil-bearing layer using single-grain OSL is considered an Arated method for indirectly dating fossils and is readily applicable to undisturbed sediment ${ }^{11}$. We applied the OSL dating technique to all of our fossil sites and these returned viable results (Table 2, Supplementary Note 5). The combined geological, taphonomic, faunal, floral and chronometric studies support an undisturbed primary context for the fossil deposits and their remains, thus by combining $\mathrm{A}^{*}$ or A-rated dating techniques and using multiple independent laboratories to do so we are confident that the chronometric ages obtained for each site are of high quality and thus reliable ${ }^{11}$ (Table 2, Methods and Supplementary Notes 1-9).

The chronometric ages for the four sites are summarised in Table 2 with detailed methodology and datasets provided in the Methods section and Supplementary Notes 1-9. Together, the four sites span $\sim 20,000$ years from $\sim 60$ to $\sim 40 \mathrm{ka}$. The oldest fossil-bearing layer occurs at SWJ, which has a maximum weighted mean OSL age of $65.6 \pm 2.2 \mathrm{ka}(n=6)$. The next youngest fossil layers occur at SWCC, which has a weighted mean OSL age of $58.2 \pm 6.1 \mathrm{ka}(n=2)$, and SW3 which has a weighted mean OSL age of $47.7 \pm 3.2 \mathrm{ka}(n=5)$. The youngest fossil deposit which occurs at SW9 has a weighted mean age of $40.1 \pm 1.7 \mathrm{ka}$ ( $n$ $=24$ ), which has been calculated from 19 OSL ages and 5 US-ESR ages (Tables $1 \& 2$, Supplementary Notes 5-8).

Extinctions coincide with environmental deterioration. The known limitations of the fossil record, such as those described by the Signor-Lipps effect ${ }^{39}$, can bias the estimated timing of extinction for a fossil taxon ${ }^{40}$. Therefore, the youngest fossil record for a particular taxon should only be considered as 


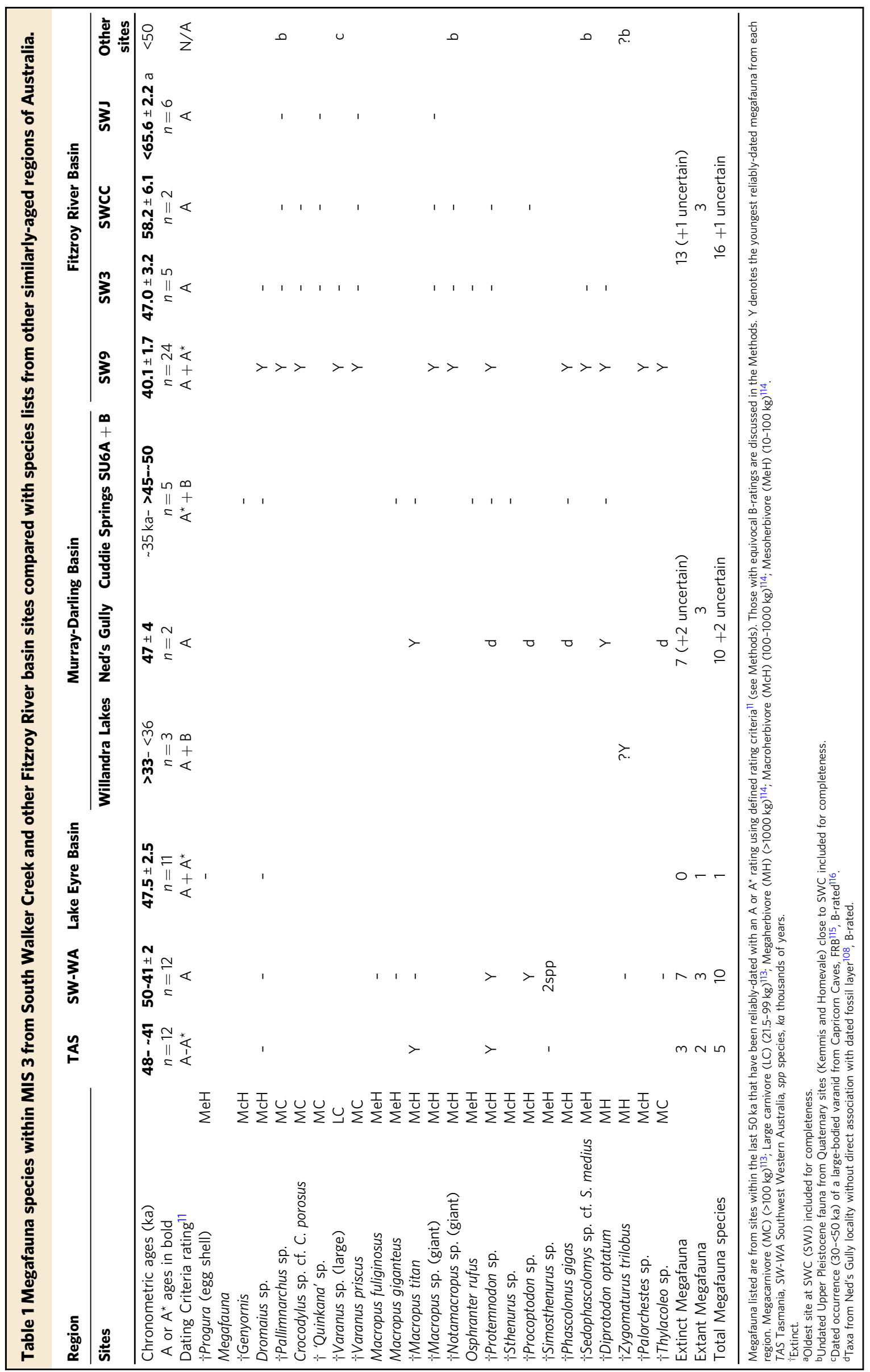




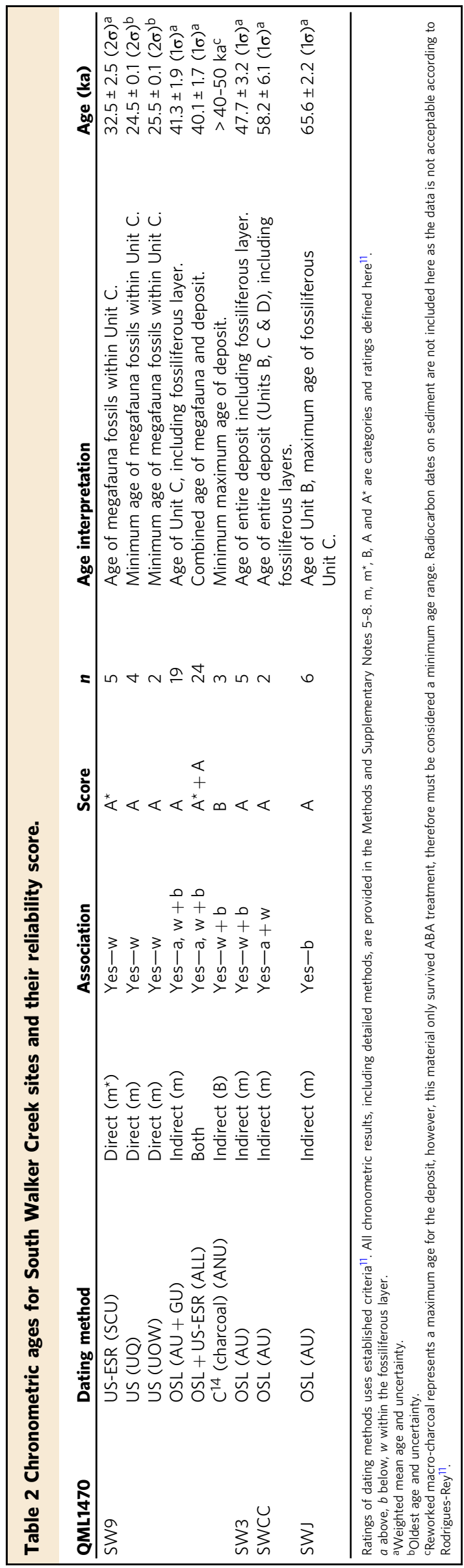

indicative of the last appearance of an extinct taxon, not its true time of extinction. With this in mind, we can conclude that the extinct megafauna taxa at SWC suffered local extinction sometime after their youngest last appearance age at SW9, which is $40.1 \pm 1.7 \mathrm{ka}$.

With our new fauna and chronology in mind, we investigated available palaeoenvironmental proxies, in particular those recording regional and local changes that are likely to have impacted the survival of megafauna (e.g. water, vegetation, fire and climate). Hydroclimatic proxies that include palaeomonsoon activity, catchment flow and lake levels are available for northern Australia and the three basins associated with our fauna, the FRB, LEB and MDB. Chronologically staggered and abrupt hydroclimatic deterioration starts around $48 \mathrm{ka}$ in the $\mathrm{LEB}^{20,28}$ (Fig. 3a), then from $45 \mathrm{ka}$ in the $\mathrm{MDB}^{25,26,28}$ (Fig. $3 \mathrm{~b}$ and c), and then from $40 \mathrm{ka}$ in the $\mathrm{FRB}^{24,28}$ (Fig. 3d). Hydroclimate in northern Australia falls below present day levels after $40 \mathrm{ka}^{28,41}$ indicating a significant drying trend (Fig. 3e). Together, these records show abrupt and major fluctuations with a sustained reduction in effective rainfall reaching the watersheds of the LEB, MDB and FRB from $48 \mathrm{ka}$ and lasting until at least $30 \mathrm{ka}$. Within each basin, the youngest reliably-dated megafauna occur during, or just prior to, the onset of abrupt hydroclimatic deterioration (Fig. 3a-e). Given that the extinction of these megafauna occurred after their last appearances, we infer that local extinctions in these basins occurred during abrupt deterioration in hydroclimate.

The correspondence between the staggered chronologies of both the youngest megafauna and the onset of sustained hydroclimatic deterioration for each basin suggests hydroclimatic change as a possible driver of catchment-based extinctions, occurring first in the LEB, then in the MDB and then in the FRB. The sustained loss of effective catchment flow within the FRB would not favour survival of aquatically-dependent megafauna, such as the three crocodilians. Crocodylus likely survived this inland deterioration by occupying viable coastal environments whilst Pallimnarchus and 'Quinkana' did not. At some point since $30 \mathrm{ka}$ the hydroclimate of the FRB returned to levels similar to that experienced prior to $40 \mathrm{ka}$, presumably after the Last Glacial Maximum; however, the aquatic environments that were once conducive for crocodilians at SWC did not return indicating that the hydrological system was irrevocably altered.

We acknowledge that for open sites there may be reduced preservation potential of vertebrate remains due to the deterioration of the hydroclimate; therefore, a taphonomic bias against the preservation of younger sites may have occurred as the hydroclimate deteriorated. This potential bias of preservation can be reconciled with the discovery of reliably-dated sites within these basins that preserve only extant megafauna.

In addition to hydroclimate, we investigated Quaternary proxy records of vegetation ${ }^{23,27,42}$, fire , $^{15,27,42,43}$ and climate change 24,44 from east of the Great Dividing Range in Queensland. These records represent palaeoenvironmental proxies closest to our sites and likely better reflect more direct environmental changes influencing megafaunal survival. Palynological data from the offshore ODP82027 drill record is the most appropriate for indicating changes in vegetation and fire frequency relevant to our locality because it preserves a signal that is not constrained by local terrestrial site depositional biases ${ }^{45}$. This record indicates an overall drying with sustained reduction of complex rainforest beginning $\sim 50 \mathrm{ka}$. Importantly, there is a regional reduction in grasslands (sclerophyll herbs), which is a key dietary component of herbivorous megafauna. This reduction begins around $50 \mathrm{ka}$ and reaches its lowest levels for the entire record at $\sim 35 \mathrm{ka}$ (Fig. 3f). Arboreal sclerophyll taxa (e.g. Eucalyptus, Melaleuca, Acacia and Casuarinaceae) generally follow the same trends seen in sclerophyll herbs over the last $250 \mathrm{kyr}^{23}$; however, they 


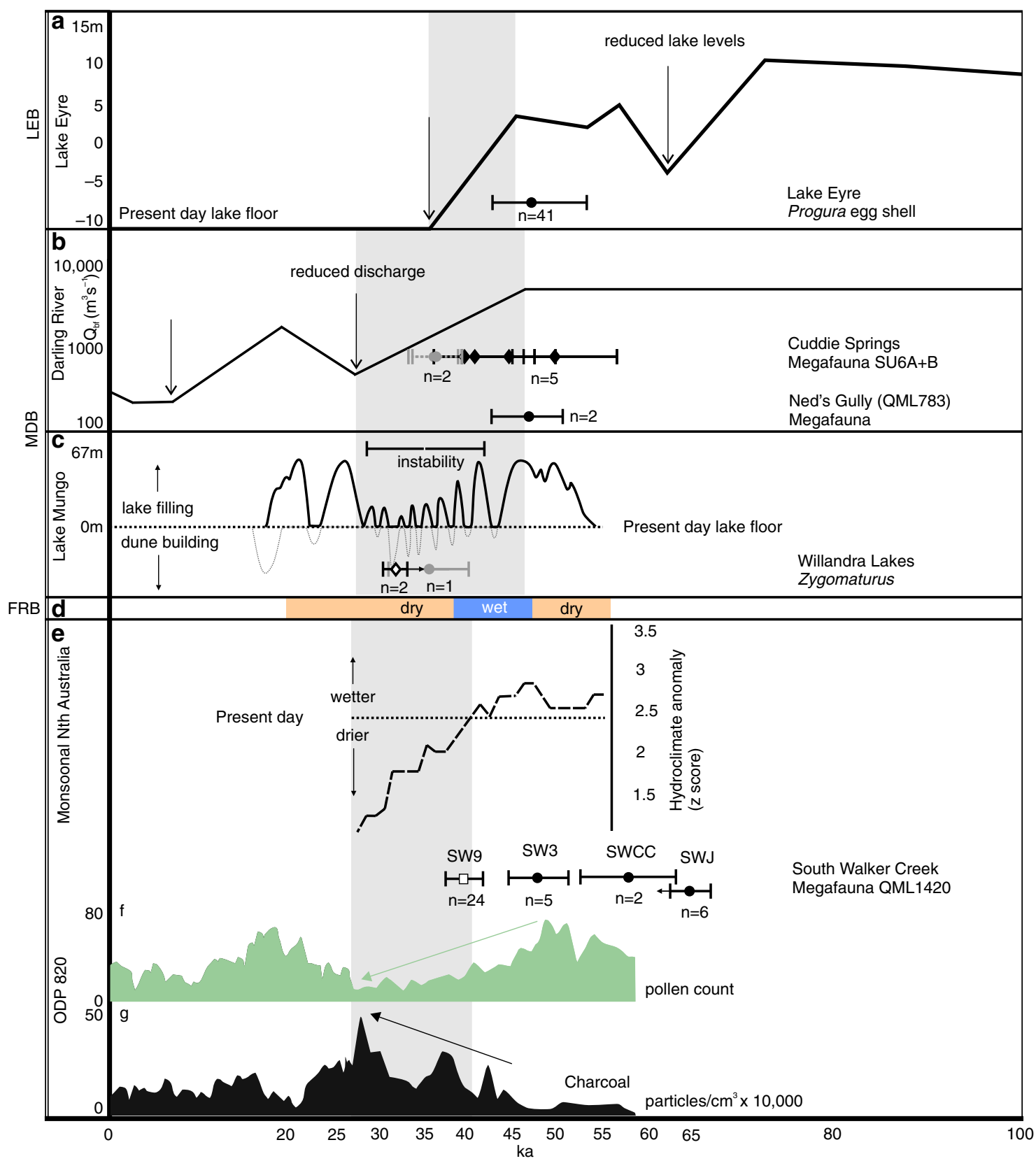

Fig. 3 Regional hydroclimate and local palaeoenvironmental proxies since $\mathbf{1 0 0}$ ka compared with young megafauna sites from the Lake Eyre, MurrayDarling and Fitzroy River basins. a Hydroclimatic proxies include Kati Thanda-Lake Eyre levels (adapted from ref. ${ }^{20}$ ). b Palaeodischarge of the Darling River (adapted from ref. ${ }^{26}$ ). c Mungo Lake levels and dune development (adapted from ref. ${ }^{25}$ ). d FRB catchment activity (adapted from refs. ${ }^{24,} 28$ ). e Hydroclimate relative to present day of northern monsoonal Australia (adapted from ref. ${ }^{28}$ ). $\mathbf{f}$ Local palaeoenvironmental proxies including counts of grass pollen (Poaceae) (f) and micro-charcoal ( $(\mathbf{g})$ from ODP 820 (adapted from ref. ${ }^{27}$ ). Young megafauna sites within each basin are plotted using A or A* quality-rated ages (black plots) (Table 1). All SWC sites are plotted here for completeness. Published OSL ages for Cuddie Springs ${ }^{55}$ and the Willandra Lakes Zygomaturus ${ }^{107}$ are B-rated here but are equivocal so we have included them (plotted in grey). Extinctions are interpreted as occurring sometime after the youngest $A$ or $A^{\star}$ age. Note the timing of onset of trajectory of hydroclimatic deterioration (light grey bars) within each region and megafauna

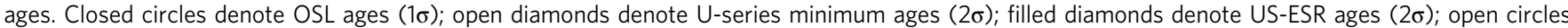

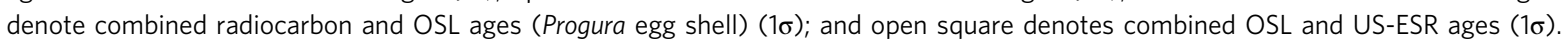

approximately double their proportional representation after $\sim 36-35 \mathrm{ka}^{23,27,42}$ indicating a sustained change in the sclerophyllous vegetation structure along the eastern seaboard.

Our palynological assessment of SW9 shows similarities to the regional pollen record of ODP820 and the local record at Lynch's Crater $^{46}$ during MIS 3. The overall taxonomic composition of pollen taxa at SW9 is also similar to that of the present day SWC area (Supplementary Note 9, Supplementary Fig. 34 and Supplementary Table 23), therefore, this indicates limited change in floral composition since the deposition of SW9 $\sim 40 \mathrm{ka}$. A greater proportional representation of arboreal sclerophyllous taxa compared with low counts of sclerophyllous herbs (e.g. Poaceae) is surprising but may be indicative of the observed regional reduction of grasslands from 50 to $35 \mathrm{ka}$ and suggests 
suboptimal forage for the grazing megafauna. The dominance of arboreal sclerophyllous taxa may also be indicative of the transition to a more dominant arboreal sclerophyll vegetation structure recorded later in MIS 3 further to the north $23,27,46$.

The ODP820 charcoal record illustrates an increased fire frequency starting $\sim 44 \mathrm{ka}$, intensifies from $\sim 40 \mathrm{ka}$, and peaking $\sim 28 \mathrm{ka}^{23,27,43}$ (Fig. 3g). While anthropogenic landscape burning has been attributed to these increases over the last 50,000 years 27,43 , this has been challenged and a more likely explanation involves the complex relationship between climate and vegetation with fire frequency ${ }^{47}$. Importantly, the increased and sustained burning from $\sim 44 \mathrm{ka}$ indicates a fundamental shift toward environmental deterioration and instability that would have impacted the survival of megafauna. The extinction of grazing megafauna sometime after $\sim 40 \mathrm{ka}$ would have reduced grazing pressure on grasslands and potentially created the conditions favouring intensified burning ${ }^{48,49}$, and possibly contributing to the peak in burning seen regionally around $28 \mathrm{ka}$. Our assessment of charcoal particles at SW9 (Supplementary Note 9) demonstrates preservable indicators of fire within the environment; however, these results will be uninformative until a longer sequence is available to assess and compare relative charcoal frequencies through time as well as any taphonomic bias within this alluvial system.

Together, the multiple proxies investigated here show regionally sustained vegetation change with reduction of grasslands and a sustained higher representation of arboreal sclerophyll taxa, which is also reflected locally at SWC. These vegetation changes occurred alongside sustained and intensified fire along with reduced catchment flow and thus available free water. Such deterioration of the environment is set within a backdrop of intensifying aridity ${ }^{28}$. The culmination of these changes would have impacted terrestrial megafauna survival, especially the herbivores and more specifically the grazers. These negative impacts from a deteriorating environment on herbivorous megafauna survival would likewise have affected the hypercarnivorous megafauna.

The SWC megafauna were a diverse aquatic and terrestrial megafauna community, occurring locally from at least $60 \mathrm{ka}$ until $40.1 \pm 1.7 \mathrm{ka}$, with their local extinction occurring sometime after this. The regional environmental changes that began $\sim 48-50 \mathrm{ka}$ did not have an obvious or immediate impact. However, we propose that the intensification of environmental deterioration and instability starting $\sim 40-41$ ka played a key role in their local extinction (Fig. 3).

Reduction of the Sporormiella dung fungus occurring around $41 \mathrm{ka}$ at Lynch's Crater, $560 \mathrm{~km}$ north of SWC, has been used as a proxy for both the presence of megaherbivores and their rapid population decline to extinction ${ }^{15,16}$. However, the use of Sporormiella as a megaherbivore proxy has been challenged on taphonomic and biological grounds $10,18,19,50,51$. Variable concentrations of Sporormiella spores are present in the sediment samples taken at SW9 for palynological assessment (Supplementary Note 9, Supplementary Table 23). Some samples indicate high concentrations similar to those recovered from Lynch's Crater ${ }^{15}$ and off-shore Western Australia ${ }^{16}$; however, it is unclear whether there are other depositional or taphonomic biases at play in the fluvial system that can explain such variation in concentrations. Therefore, the presence of some high concentrations of Sporormiella potentially supports the presence of megaherbivores within the environment at the time of SW9 deposition; however, this will remain equivocal until a detailed assessment of depositional and taphonomic biases is undertaken.

A role for people in the extinction of Sahul megafauna through their direct extirpation has been previously proposed. However, with no evidence of butchery or kill sites, it has been proposed that extinction occurred rapidly across Sahul shortly after human arrival $^{12-14,22,52-55}$. In the absence of evidence for direct extirpation, indirect human-mediated factors such as landscape burning have been proposed but are difficult to differentiate from non-human factors $15,16,21,56,57$.

The occupation of Sahul most-likely occurred in northwest Sahul, at least $50 \mathrm{ka}^{58,59}$ or as early as $65 \mathrm{ka}^{60}$, with much of mainland Australia inhabited by $45 \mathrm{ka}^{61-63}$. People most-likely dispersed across the continent via migratory routes either reflecting connectivity to available freshwater ${ }^{64}$ or first along coastal routes and then dispersing inland ${ }^{65}$. Therefore, under a human-driven extinction scenario where megafauna suffer extinction shortly after human arrival it would be expected that megafauna would suffer extinction first in the north and then along the continental periphery of Sahul before extinction occurred in southern and interior regions.

SWC represents the most northerly and the only diverse megafauna site from the easterly-draining seaboard to be reliablydated within the period of human occupation of Sahul. Therefore, it is well situated to test these scenarios. If the youngest megafauna ages in an area are considered to be the closest age approximation for their extinction, then the most reliable records indicate that extinctions occurred first within the interior (e.g. LEB) after $48 \mathrm{ka}$, then within the southern MDB after $45 \mathrm{ka}$; and then around the continental periphery (e.g. southwest Western Australia, Tasmania and SWC) after 41-40 ka (Table 1). This result is contrary to what would be expected and so our assessment does not support rapid or synchronous continentalwide extinction of megafauna by people.

Based on what archaeological evidence is available, we cannot firmly place people at SWC, or within the FRB, at the time the fossil deposits formed. The oldest archaeological record closest to SWC has an occupation age of $\sim 19 \mathrm{ka}$ at Kenniff Cave ${ }^{66}$, Carnarvon Gorge, $\sim 380 \mathrm{~km}$ south of SWC. The earliest evidence for human occupation, that is closest to the FRB, comes from two sites over $660 \mathrm{~km}$ to the north and northwest of SWC. The two locations, Gledswood Shelter ${ }^{67}$ and Ngarrabullgan ${ }^{61}$, record human occupation at or younger than $40 \mathrm{ka}$ and occur within the north and westerly-draining Flinders and Mitchell River Basins of Gulf of Carpentaria. Neither basin shares topographic or hydrological connection with the FRB to the southeast.

With no evidence for a human presence within the FRB before $\sim 19 \mathrm{ka}$, or even more regionally before $40 \mathrm{ka}$, we cannot implicate people in the extinction of the SWC megafauna. Acknowledging the limited number of archaeological sites older than $\sim 30 \mathrm{ka}$ from eastern Sahul ${ }^{57,68}$ we cannot rule out that this absence is a result of significant under sampling, therefore, future concentrated field effort in eastern Sahul may establish an archaeological record older than $40 \mathrm{ka}$.

\section{Discussion}

Our discoveries provide the first reliably-dated occurrences for several megafauna taxa within the last $50 \mathrm{ka}$, including all three crocodilians, Varanus priscus, Palorchestes, Sedophascolomys, and at least two macropodids including the largest species known. This increases the total number of megafauna species present at the time of human arrival in Sahul to at least 24. Our new record refutes the claimed extinction timing of Pallimnarchus ${ }^{69}$ and the modelled extinction timing for Palorchestes, Thylacoleo, and megafauna representatives of Macropus ${ }^{14}$. These new records also document biogeographic extension into north-eastern Australia of several taxa during MIS 3, including Thylacoleo, Phascolonus, Diprotodon and Protemnodon. Furthermore, the number of megafauna species identified at our youngest site is greater than that of similar-aged megafauna sites elsewhere in Australia, 
increasing the number of taxa surviving the modelled ${ }^{14}$ peak of extinction to 13. This amounts to more than half the total number of species now confirmed to be present in Sahul during human occupation.

The age and north-eastern location of our megafauna assemblage is contrary to that which would be expected if continentalwide extinction was human-mediated through direct hunting, where extinctions shortly followed the currently proposed timing and route of human migration across Sahul. Instead, our results favour a scenario of local changes in catchment flow, vegetation structure and fire regime that was not conducive to the survival of aquatic and terrestrial megafauna. These changes should be considered within the context of a regional backdrop of spatiotemporally staggered hydroclimatic deterioration and instability from $\sim 48 \mathrm{ka}$ that occurred across major interior, southern and eastern drainage basins.

Our understanding of the local and regional impacts of environmental deterioration during MIS 3 on megafauna in northern Sahul must also be considered within the context of much longer-term hydroclimate deterioration ${ }^{70-74}$ and vegetation change ${ }^{23,70,75}$ that was underway since the Middle Pleistocene, well before human occupation. These earlier changes have been implicated in major faunal ${ }^{4}$ and floral $^{23}$ turnovers in northeast Australia, and yet similar turnovers are not recorded in southern Australian sites spanning similar timeframes ${ }^{5,76}$. Therefore the timing of environmental deterioration and the subsequent responses of fauna and flora differ between regions of Sahul, and have done so across much of the Quaternary. Therefore, more complex scenarios are needed to explain extinctions that take into account these spatio-temporal differences.

\section{Methods}

Fossil collection and taxonomic identifications. We employed standard palaeontological and geological procedures during the excavation, including the mapping and recording of positions and associations of fossil remains within the stratigraphic and sedimentological context for each site. Taxonomic identifications were undertaken through indirect comparative assessment via available literature or through direct comparisons with collections held at the Queensland Museum, Museums Victoria, Australian Museum and South Australian Museum (Supplementary Notes 1-4).

Geochronology. Dating samples were collected during field excavation and laboratory preparation from 2009 to 2017, with focus on collecting adequate material to undertake multidisciplinary age assessments using four independent dating techniques, specifically optically stimulated luminescence (OSL); radiocarbon $\left({ }^{14} \mathrm{C}\right)$, uranium series (US), and combined US and Electron Spin Resonance (US-ESR) dating. All sites were sampled; however, due to the poor quality of some samples, not every technique could be applied successfully across all sites. OSL dating has been applied across all sites and via two independent laboratories (Griffith University (GU) and The University of Adelaide (UA)). ${ }^{14} \mathrm{C}$ and U-series assessments were undertaken by two independent laboratories $\left({ }^{14} \mathrm{C}\right.$ by Beta Analytic (Beta) and Australian National University (ANU)) and U-series by The University of Queensland (UQ) and University of Wollongong (UOW). ESR assessment was undertaken by a single laboratory at Southern Cross University (SCU).

The matrix depositional age was assessed using OSL, whilst the age of the organic inclusions (teeth/bones/charcoal/organic sediment) was assessed using ${ }^{14} \mathrm{C}$, US and ESR. OSL measurements were undertaken independently at GU and UA, and the various burial dose datasets were then analysed using a combined data approach. Associated fossilised teeth were assessed using US, ESR, and combined US-ESR to determine the uptake history of the fossils and allow modelling of finite numerical ages. Attempts were made to radiocarbon date bones, teeth, charcoal and sediment using a variety of pre-treatment methods. Unfortunately, no megafauna could be directly dated due to a lack of collagen. The radiocarbon methods which could be applied to macro-charcoal produced minimum age estimates only. Detailed methodologies are provided in Supplementary Notes 5-8 for all dating techniques used.

Optically stimulated luminescence. OSL core samples were collected by QM in 2009, 2011, 2015 and 2016 using extraction techniques and methodologies provided by GU laboratory and through best practice literature (see Supplementary Note 5). This included choosing sampling localities that (1) were freshly exposed through excavation into cohesive sedimentary matrix; (2) avoided areas showing sediment introduction via recent or old sediment cracking; (3) entirely avoided unconformities, major lithological boundaries and complex sedimentary matrices (4) were positioned at least $20-30 \mathrm{~cm}$ below the exposed ground surface to avoid inaccuracies in gamma dose rates determined using ex situ (laboratory-based) dosimetry techniques. Sediment samples were taken from above and below each core at a radius of between 15 and $20 \mathrm{~cm}$ for sedimentological, high-resolution gamma spectrometry (HRGS) and water content assessments. Where possible, OSI core samples were collected in vertical and horizontal sequences to provide both stratigraphic and duplicate samples for any particular layer, including samples taken specifically above, within and below the fossiliferous horizons.

Additional OSL samples were collected by UA in 2017, and included the use of in situ gamma-ray spectrometry (NaI:Tl crystal) to measure external gamma dose rates via the energy windows method ${ }^{77}$. Low-level beta counting was conducted on homogenised sediment collected from the OSL sampling holes to determine external beta dose rates. Conversion and attenuation factors ${ }^{78-80}$ were applied to determine the gamma and beta components of the total dose rate. The dose rate contributions from cosmic-rays have been calculated using previous approaches ${ }^{81}$ The beta, gamma and cosmic-ray dose rates have been corrected for long-term sediment moisture contents ${ }^{82}$, which were taken to be $40 \%$ of the saturated water content following assessments made on samples from freshly-dug pits across various sites.

Quartz grains (212-250- $\mu$ m diameter) from the 2015 and 2017 samples were purified at UA following standard laboratory procedures ${ }^{83}$, including the removal of the alpha-irradiated grain margins through treatment with $48 \%$ hydrofluoric acid $(40 \mathrm{~min})^{84}$. Equivalent dose $\left(D_{\mathrm{e}}\right)$ values were determined for single quartz grains using the single aliquot regenerative dose (SAR) procedure ${ }^{85}$ and only accepted for dating purposes if they satisfied a series of quality assurance criteria ${ }^{86}$. Single-grain $D_{\mathrm{e}}$ measurements were made using the experimental apparatus described by Dumero et al. ${ }^{87}$ and Méndez-Quintas et al. ${ }^{88}$ after manually loading quartz grains into standard single-grain aluminium discs drilled with an array of $300 \times 300-\mu \mathrm{m}$ holes.

The single-grain quartz $D_{\mathrm{e}}$ measurement procedures employed by GU for the 2009, 2011 and 2016 samples are as described above, with the exception that the 180-212 $\mu \mathrm{m}$ diameter quartz fractions which were isolated for dating using the single-grain quality assurance criteria $^{89}$ (see Supplementary Note 5).

We have considered a range of statistical age models to characterise each singlegrain $D_{\mathrm{e}}$ distribution and to derive representative burial dose estimates for the AU and GU OSL samples (central age model (CAM), the three-parameter minimum age model (MAM-3), the four-parameter minimum age model (MAM-4) and the finite mixture model (FMM) 90,91 . The rationale behind the age model choice for each sample is provided in Supplementary Note 5, and is based on consideration of $D_{\mathrm{e}}$ overdispersion, the presence of discrete dose populations, and the statistical suitability of the various age model fits (maximum log likelihood criterion) ${ }^{92}$. The same age model selection criteria have been applied to both the AU and GU $D_{\mathrm{e}}$ datasets to ensure consistency with the final OSL age evaluations. The software, $R$ (luminescent package), was used for the evaluation of the equivalent dose and modelling distributions for CAM and MAM (see Code availability).

Uranium-series dating. Several fossil teeth were directly dated using U-series methods (see Supplementary Notes 7 \& 8). This included both micro-drilling and laser ablation of dentine with subsequent measurement using multi-collector inductively coupled plasma mass spectrometers (MC-ICP-MS). For micro-drilling, multiple powdered dentine samples were collected with a 1-mm diameter stainless steel hand drill bit through the respective teeth following standard techniques ${ }^{93}$. This allowed for the construction of both U-concentration and ${ }^{230} \mathrm{Th}$-age profiles though the teeth, thus, allowing investigation of the mode of U-uptake/loss in the teeth, and essentially, the reliability of the resulting ages. The micro-drilled dentine samples were measured at Radiogenic Isotope Facility, The University of Queensland. using a Nu Plasma MC-ICP-MS following the laboratory's standard protocols 94

Open-system U-series dating of the teeth via laser ablation MC-ICP-MS was undertaken at the Wollongong Isotope Geochronology Laboratory, University of Wollongong. Laser ablation was performed on a NWR 193 excimer laser coupled to a MC-ICPMS Thermos Plus, at parameters of fluence of $0.9 \mathrm{~J} / \mathrm{cm}^{2}$, pulse rate of $10 \mathrm{~Hz}$, spot size of $150 \mu \mathrm{m}$ and scan speed of $5 \mu \mathrm{m} / \mathrm{s}$. Helium was used as a carrier gas at a flow rate of $0.9 \mathrm{~L} / \mathrm{min}$. Before and after each sample, three rasters were done on NIST612, MK10 (a MIS 7 coral used as primary standard ${ }^{95}$ ) and MK16 (a MIS 5 coral used as secondary standard). Measured ${ }^{234} \mathrm{U} /{ }^{238} \mathrm{U}$ and ${ }^{230} \mathrm{Th} /{ }^{238} \mathrm{U}$ isotopic ratios were corrected for elemental fractionation and Faraday cup/SEM yield by comparison with MK10 coral (see above) for which ratios were previously characterised internally by solution analysis. Background subtraction, concentration quantification and ratio corrections were performed using Iolite ${ }^{\mathrm{ts}}$ software. Open-system U-Th ages were modelled following the DiffusionAdsorption-Decay model ${ }^{96}$ and using the UThwigl R package ${ }^{97}$ (see Code availability).

Combined $\mathbf{U}$-series and electron spin resonance dating. ESR dating was performed on a Freiberg MS5000 X-band, coupled to a X-ray Varian irradiator. ESR measurements were performed at $1 \mathrm{G}$ modulation amplitude, $2 \mathrm{~mW}$ power, 100G 
sweep, $100 \mathrm{kHz}$ modulation frequency, while sequence of $90 \mathrm{~s}, 380 \mathrm{~s}, 900 \mathrm{~s}, 1800 \mathrm{~s}$, $3600,7200,14,400 \mathrm{~s}$ was undertaken at $40 \mathrm{kV}$ voltage and $0.5 \mathrm{~mA}$ current. For each irradiation step the fragment was measured over $180^{\circ}$ in $x, y$ and $z$-configurations with a $20^{\circ}$ step. Dose response curve (DRC) and equivalent dose $\left(D_{\mathrm{e}}\right)$ were calculated using the MCDoseE 2.0 program ${ }^{98}$. The external dose was calculated using the values obtained by the gamma spectrometer measurements in the field.

Radiocarbon dating. Attempts to date bones, teeth and macro-charcoal at BetaAnalytic using their standard collagen and carbon pre-treatment techniques (Supplementary Note 6) were unsuccessful as no collagen was preserved and macro-charcoal did not survive the processing. Instead bulk organics were extracted and dated from the sediments instead. Radiocarbon dates on sediments are notoriously unreliable given the multiple sources of carbon present, each of which may have a different age. Charcoal found within the fossiliferous layer was dated at the Australian National University using techniques outlined in Supplementary Note 6 . Unfortunately, samples were too small and/or too poorly preserved for acid base oxidation-stepped combustion techniques (ABOx-SC), and were cleaned with an acid-base-acid (ABA) protocol. This protocol does not effectively remove contaminants, and the radiocarbon dates on charcoal must be regarded as minimum age estimates. This complicates interpretation as charcoal in fluvial deposits can be considerably older than the deposition of the sediment. We suspect that the macro-charcoal pieces assessed in the fossiliferous layer are reworked within clay-rich rip-up clasts that are observed within the fossiliferous layer but likely derive from older scoured alluvial sediments (Supplementary Notes 4 \& 6)

Palynological assessment. Clay-rich matrix was sampled from QML1470 SW9 that preserved macroplant fossil remains. These samples were then subsampled for palynological assessment (Supplementary Note 9). Ten subsamples were processed to assess the palynological concentrate to determine the floral diversity of the site (Supplementary Fig. 34 and Supplementary Table 23). Each subsample ( 10 g of sediment) was analysed using a method developed for pollen extraction from marine sediments, i.e. low organic content ${ }^{99}$ and successfully applied to a range of depositional settings ${ }^{100}$. Samples are deflocculated in sodium pyrophosphate $(10 \%)$ and then using sodium polytungstate heavy liquid (specific gravity of 1.9) to separate the palynomorph rich organic layer from the mineral clay fraction of the sediment. The pollen concentrate then underwent acetolysis using a 9 to 1 mixture of acetic anhydride and concentrated sulphuric acid. Samples were then placed in glycerol for pollen and micro-charcoal (particles $<125 \mu \mathrm{m}$ ) counting using a $\times 400$ compound light microscope.

Quality assessment and choice of fossil ages. Applying selective criteria when choosing or rating the quality of dates for Quaternary-aged fossil fauna is an area of evolving study and refinement ${ }^{11,12,101,102}$. We follow established criteria for assessing the quality of dating techniques used to choose the most reliable ages for megafauna fossils in Sahul ${ }^{11}$ dating from MIS 3 (Fig. 1 and Table 1). We apply these same criteria to our own results (Table 2). Those considered to be reliable (e.g. rating of $\mathrm{A}$ or $\mathrm{A}^{*}$ ) were preferred over those that were considered unreliable (e.g. rating of $\mathrm{B}$ or $\mathrm{C}$ ). We then used these same ages to place the youngest records of megafauna within their respective catchments and relate these to available palaeoenvironmental proxies recorded for each catchment and region, thus relating these patterns to our location within the Fitzroy River Basin (Fig. 3).

Youngest high quality-rated megafauna fossil ages are provided in Table 1. Megafauna fossils from Tasmania were directly dated using radiocarbon ${ }^{103}$ and were $A^{*}$-rated ${ }^{11}$. Sediment containing megafauna fossils from southwest Western Australia were dated using associated speleothem (U-series) and sediments (OSL) and were A-rated ${ }^{30,104}$. Egg shell from the LEB has been dated using radiocarbon, OSL and amino acid racemisation, including remains previously identified as the extinct giant flightless bird Genyornis and the extant Emu Dromaius ${ }^{105}$. The egg shell identified as Genyornis has been challenged and is now identified as a species of megapode Progura ${ }^{106}$. Progura does not meet our mass definition of megafauna; however, we will use it to represent faunal extinction in the LEB. Based on the direct and indirect dating methods applied to these egg shells the ages are $A^{*}$ and A-rated. A specimen of Zygomaturus from Willandra Lakes ${ }^{107}$ within the MDB was dated using U-series laser ablation applied to bone, returning a minimum age estimate. Sediment found with the specimen was also dated using OSL; however, a lack of field data renders the sediment association uncertain. Therefore a rating of $A$ and $B$ is applied here for the U-series and OSL dates, respectively, with the Useries minimum age preferred. Articulated megafauna remains from the upper Darling River system (Ned's Gully) have been dated using OSL from within the fossil-bearing layer ${ }^{12}$; however, many of the fauna listed from this site ${ }^{12}$ lack direct association with the fossil layer ${ }^{108}$. Therefore, we have A-rated the fauna known from the fossil layer and B-rated the fauna with unconfirmed association with the dated fossil layer. Megafauna recovered from Units 6A and 6B, from Cuddie Springs, northern New South Wales, have been dated using $A^{*}$-rated US-ESR and A-rated OSL methods. The US-ESR ages ${ }^{69}$ are consistently older than the OSL ages ${ }^{12}$ which may reflect fossil reworking, sediment mixing, or both at the site $^{69,109,110}$. This conclusion has been questioned ${ }^{53}$; however, based on the uncertainty surrounding the OSL ages they are B-rated. We acknowledge the uncertainty surrounding the age of megafauna at Cuddie Springs and thus present an age range in Table 1 , including $\mathrm{A}^{*}$ and $\mathrm{B}$-rated ages.

Reporting summary. Further information on research design is available in the Nature Research Reporting Summary linked to this article.

\section{Data availability}

The authors declare that data supporting the findings of this study are available in this published article and its supplementary information files. The source data underlying Supplementary Figs. 4 and 9 are provided as a Source Data file.

\section{Code availability}

UThwigl R package is available at https://doi.org/10.17605/OSF.IO/D5P7S. R (luminescent package) is available at https://cran.r-project.org/web/packages/Luminescence/index.html.

Received: 27 August 2019; Accepted: 27 March 2020; Published online: 18 May 2020

\section{References}

1. Martin, P. S. \& Klein, R. G. Quaternary Extinctions: A Prehistoric Revolution (University of Arizona Press, 1984).

2. Long, J. A., Archer, M., Flannery, T. \& Hand, S. Prehistoric Mammals of Australia and New Guinea: One Hundred Million Years of Evolution (JHU Press, 2002).

3. Price, G. J. \& Webb, G. E. Late Pleistocene sedimentology, taphonomy and megafauna extinction on the Darling Downs, southeastern Queensland. Aust. J. Earth Sci. 53, 947-970 (2006).

4. Hocknull, S. A., Zhao, J.-X., Feng, Y.-X. \& Webb, G. E. Responses of Quaternary rainforest vertebrates to climate change in Australia. Earth Planet. Sci. Lett. 264, 317-331 (2007).

5. Prideaux, G. J. et al. An arid-adapted middle Pleistocene vertebrate fauna from south-central Australia. Nature 445, 422 (2007).

6. Prideaux, G. Systematics and Evolution of the Sthenurine Kangaroos. Vol. 146 (University of California Press, 2004).

7. Price, G. J. Taxonomy and palaeobiology of the largest-ever marsupial, Diprotodon (Diprotodontidae, Marsupialia). Zool. J. Linn. Soc. 153, 369-397 (2008)

8. Hocknull, S. A. et al. Dragon's paradise lost: palaeobiogeography, evolution and extinction of the largest-ever terrestrial lizards (varanidae). PLOS ONE 4, e7241 (2009).

9. Wroe, S. et al. Climate change frames debate over the extinction of megafauna in Sahul (Pleistocene Australia-New Guinea). Proc. Natl Acad. Sci. USA 110 8777-8781 (2013)

10. Price, G. J., Louys, J., Faith, J. T., Lorenzen, E. \& Westaway, M. C. Big data little help in megafauna mysteries. Nature 558, 23 (2018).

11. Rodríguez-Rey, M. et al. Criteria for assessing the quality of Middle Pleistocene to Holocene vertebrate fossil ages. Quat. Geochronol. 30, 69-79 (2015).

12. Roberts, R. G. et al. New ages for the last Australian megafauna: continentwide extinction about 46,000 years ago. Science 292, 1888-1892 (2001).

13. Wroe, S. \& Field, J. A review of the evidence for a human role in the extinction of Australian megafauna and an alternative interpretation. Quat. Sci. Rev. 25, 2692-2703 (2006)

14. Saltre', Fdr et al. Climate change not to blame for late Quaternary megafauna extinctions in Australia. Nat. Commun. 7, 10511 (2016).

15. Rule, S. et al. The aftermath of megafaunal extinction: ecosystem transformation in Pleistocene Australia. Science 335, 1483-1486 (2012).

16. van der Kaars, S. et al. Humans rather than climate the primary cause of Pleistocene megafaunal extinction in Australia. Nat. Commun. 8, 14142 (2017)

17. Perrotti, A. G. \& van Asperen, E. Dung fungi as a proxy for megaherbivores: opportunities and limitations for archaeological applications. Vegetation Hist. Archaeobotany 28, 93-104 (2019).

18. Baker, A. G., Bhagwat, S. A. \& Willis, K. J. Do dung fungal spores make a good proxy for past distribution of large herbivores? Quat. Sci. Rev. 62, 21-31 (2013).

19. Dodson, J. \& Field, J. H. What does the occurrence of Sporormiella (Preussia) spores mean in Australian fossil sequences? J. Quat. Sci. 33, 380-392 (2018)

20. Cohen, T. J. et al. Hydrological transformation coincided with megafaunal extinction in central Australia. Geology 43, 195-198 (2015).

21. Brook, B. W. et al. Lack of chronological support for stepwise prehuman extinctions of Australian megafauna. Proc. Natl Acad. Sci. USA 110, E3368 (2013). 
22. Johnson, C. N. et al. What caused extinction of the Pleistocene megafauna of Sahul? Proceedings. Bio. Sci. 283, https://doi.org/10.1098/rspb.2015.2399 (2016).

23. Moss, P. T. \& Kershaw, A. P. A late Quaternary marine palynological record (oxygen isotope stages 1 to 7 ) for the humid tropics of northeastern Australia based on ODP Site 820. Palaeogeogr., Palaeoclimatol., Palaeoecol. 251, 4-22 (2007).

24. Croke, J., Jansen, J. D., Amos, K. \& Pietsch, T. J. A 100 ka record of fluvial activity in the Fitzroy River Basin, tropical northeastern Australia. Quat. Sci. Rev. 30, 1681-1695 (2011).

25. Bowler, J. M., Gillespie, R., Johnston, H. \& Sporcic, K. in Peopled Landscapes: (terra Australis 34) Archaeological and Biogeographic Approaches to Landscapes (ANU ePress, 2012).

26. Hesse, P. P. et al. Palaeohydrology of lowland rivers in the Murray-Darling Basin, Australia. Quat. Sci. Rev. 200, 85-105 (2018).

27. Moss, P. T. et al. A 60000-year record of environmental change for the Wet Tropics of north-eastern Australia based on the ODP 820 marine core. J. Quat. Sci. 32, 704-716 (2017).

28. Kemp, C. W., Tibby, J., Arnold, L. J. \& Barr, C. Australian hydroclimate during Marine Isotope Stage 3: A synthesis and review. Quat. Sci. Rev. 204, 94-104 (2019).

29. Block, S. et al. Where to dig for fossils: combining climate-envelope, taphonomy and discovery models. PLOS ONE 11, https://doi.org/10.1371/ journal.pone.0151090 (2016).

30. Jankowski, N. R., Gully, G. A., Jacobs, Z., Roberts, R. G. \& Prideaux, G. J. A late Quaternary vertebrate deposit in Kudjal Yolgah Cave, south-western Australia: refining regional late Pleistocene extinctions. J. Quat. Sci. 31, 538-550 (2016).

31. Molnar, R. \& Kurz, C. The distribution of Pleistocene vertebrates on the eastern Darling Downs, based on the Queensland Museum collections. Proceeds Linn. Soc. N. South Wales 117, 107-134 (1997)

32. Janis, C. M., Buttrill, K. \& Figueirido, B. Locomotion in extinct giant kangaroos: were sthenurines hop-less monsters? PLoS ONE 9, e109888 (2014).

33. Helgen, K. M., Wells, R. T., Kear, B. P., Gerdtz, W. R. \& Flannery, T. F. Ecological and evolutionary significance of sizes of giant extinct kangaroos. Aust. J. Zool. 54, https://doi.org/10.1071/zo05077 (2006).

34. Price, G. J. \& Piper, K. J. Gigantism of the Australian Diprotodon Owen 1838 (Marsupialia, Diprotodontoidea) through the Pleistocene. J. Quat. Sci.: Published Quat. Res. Assoc. 24, 1029-1038 (2009).

35. Lyman, R. L. \& Fox, G. L. A critical evaluation of bone weathering as an indication of bone assemblage formation. J. Archaeological Sci. 16, 293-317 (1989).

36. Lyman, R. L. in Vertebrate Taphonomy Cambridge Manuals in Archaeology (ed. Lee Lyman, R.) 161-222 (Cambridge University Press, 1994).

37. Evans, T. V. A Critical Evaluation of Our Understanding of Bone Transport and Deposition in Fluvial Channels (Montana State University-Bozeman, College of Letters \& Science, 2015).

38. Fernandez-Jalvo, Y. \& Andrews, P. Atlas of Taphonomic Identifications: $1001+$ Images of Fossil and Recent Mammal Bone Modification (Springer, 2016).

39. Signor, P. W. \& Lipps, J. H. in Geological Implications of Impacts of Large Asteroids and Comets on the Earth Geological Society of America Special Papers 291-296 (1982).

40. Wang, S. C. \& Marshall, C. R. Estimating times of extinction in the fossil record. Biol. Lett. 12, 20150989 (2016).

41. Krause, C. E. et al. Spatio-temporal evolution of Australasian monsoon hydroclimate over the last 40,000 years. Earth Planet. Sci. Lett. 513, 103-112 (2019).

42. Moss, P. T., Tibby, J., Petherick, L., McGowan, H. \& Barr, C. Late Quaternary vegetation history of North Stradbroke Island, Queensland, eastern Australia. Quat. Sci. Rev. 74, 257-272 (2013).

43. Thevenon, F., Bard, E., Williamson, D. \& Beaufort, L. A biomass burning record from the West Equatorial Pacific over the last $360 \mathrm{ky}$ : methodological, climatic and anthropic implications. Palaeogeogr., Palaeoclimatol., Palaeoecol. 213, 83-99 (2004).

44. Cadd, H. R. et al. Development of a southern hemisphere subtropical wetland (Welsby Lagoon, south-east Queensland, Australia) through the last glacial cycle. Quat. Sci. Rev. 202, 53-65 (2018).

45. Moss, P. T., Kershaw, A. P. \& Grindrod, J. Pollen transport and deposition in riverine and marine environments within the humid tropics of northeastern Australia. Rev. Palaeobot. Palynol. 134, 55-69 (2005).

46. Kershaw, A. P., Bretherton, S. C. \& van der Kaars, S. A complete pollen record of the last 230 ka from Lynch's Crater, north-eastern Australia. Palaeogeogr., Palaeoclimatol., Palaeoecol. 251, 23-45 (2007).

47. Mooney, S. D., Harrison, S. P., Bartlein, P. \& Stevenson, J. in Flammable Australia: Fire Regimes, Biodiversity and Ecosystems in a Changing World, 3-25 (2012).
48. Archibald, S., Bond, W., Stock, W. \& Fairbanks, D. Shaping the landscape: fire-grazer interactions in an African savanna. Ecol. Appl. 15, 96-109 (2005)

49. Archibald, S., Hempson, G. P. \& Lehmann, C. A unified framework for plant life history strategies shaped by fire and herbivory. New Phytologist 224, 1490-1503 (2019)

50. Feranec, R. S., Miller, N. G., Lothrop, J. C. \& Graham, R. W. The Sporormiella proxy and end-Pleistocene megafaunal extinction: a perspective. Quat. Int. 245, 333-338 (2011).

51. Wood, J. R. \& Wilmshurst, J. M. Wetland soil moisture complicates the use of Sporormiella to trace past herbivore populations. J. Quat. Sci. 27, 254-259 (2012).

52. Brook, B. W. \& Johnson, C. N. Selective hunting of juveniles as a cause of the imperceptible overkill of the Australian Pleistocene megafauna. Alcheringa: Australas. J. Palaeontol. 30, 39-48 (2006).

53. Field, J., Wroe, S., Trueman, C. N., Garvey, J. \& Wyatt-Spratt, S. Looking for the archaeological signature in Australian Megafaunal extinctions. Quat. Int. 285, 76-88 (2013)

54. Hamm, G. et al. Cultural innovation and megafauna interaction in the early settlement of arid Australia. Nature 539, 280 (2016)

55. Field, J., Fillios, M. \& Wroe, S. Chronological overlap between humans and megafauna in Sahul (Pleistocene Australia-New Guinea): a review of the evidence. Earth-Sci. Rev. 89, 97-115 (2008).

56. Brook, B. W. \& Bowman, D. M. Explaining the Pleistocene megafaunal extinctions: models, chronologies, and assumptions. Proc. Natl Acad. Sci. USA 99, 14624-14627 (2002)

57. Bird, M. I. et al. Humans, megafauna and environmental change in tropical Australia. J. Quat. Sci. 28, 439-452 (2013)

58. O'Connell, J. F. \& Allen, J. Dating the colonization of Sahul (Pleistocene Australia-New Guinea): a review of recent research. J. Archaeological Sci. 31, 835-853 (2004)

59. O'Connell, J. F. et al. When did Homo sapiens first reach Southeast Asia and Sahul? Proc. Natl Acad. Sci. USA 115, 8482-8490 (2018).

60. Clarkson, C. et al. Human occupation of northern Australia by 65,000 years ago. Nature 547, 306-310 (2017).

61. David, B. et al. Sediment mixing at Nonda Rock: investigations of stratigraphic integrity at an early archaeological site in northern Australia and implications for the human colonisation of the continent. J. Quat. Sci. 22, 449-479 (2007).

62. Allen, J. \& O'Connell, J. Both half right:Updating the evidence for dating first human arrivals in Sahul. Aust. Archaeol. 79, 86-108 (2016)

63. David, B. et al. 45,610-52,160 years of site and landscape occupation at Nawarla Gabarnmang, Arnhem Land plateau (northern Australia). Quat. Sci. Rev. 215, 64-85 (2019).

64. Bird, M. I., O'Grady, D. \& Ulm, S. Humans, water, and the colonization of Australia. Proc. Natl Acad. Sci. USA 113, 11477-11482 (2016).

65. Tobler, R. et al. Aboriginal mitogenomes reveal 50,000 years of regionalism in Australia. Nature 544, 180-184 (2017).

66. Reid, J. \& Ulm, S. Index of dates from archaeological sites in Queensland. Qld Archaeological Res. 12, 1 (2000).

67. Lowe, K. M., Mentzer, S. M., Wallis, L. A. \& Shulmeister, J. A multi-proxy study of anthropogenic sedimentation and human occupation of Gledswood Shelter 1: exploring an interior sandstone rockshelter in Northern Australia. Archaeological Anthropological Sci. 10, 279-304 (2018).

68. Williams, A. N., Ulm, S., Sapienza, T., Lewis, S. \& Turney, C. S. Sea-level change and demography during the last glacial termination and early Holocene across the Australian continent. Quat. Sci. Rev. 182, 144-154 (2018).

69. Grün, R. et al. ESR and U-series analyses of faunal material from Cuddie Springs, NSW, Australia: implications for the timing of the extinction of the Australian megafauna. Quat. Sci. Rev. 29, 596-610 (2010).

70. Kawamura, H., Holbourn, A. \& Kuhnt, W. Climate variability and land-ocean interactions in the Indo Pacific Warm Pool: a 460-ka palynological and organic geochemical record from the Timor Sea. Mar. Micropaleontol. 59, 1-14 (2006)

71. Peerdeman, F., Davies, P. \& Chivas, A. in Proceedings of the Ocean Drilling Program, Scientific Results, College Station, Texas (TX), 163-173 (1993).

72. Webster, J. M. \& Davies, P. J. Coral variation in two deep drill cores: significance for the Pleistocene development of the Great Barrier Reef. Sediment. Geol. 159, 61-80 (2003).

73. Nanson, G. C., East, T. J. \& Roberts, R. G. Quaternary stratigraphy, geochronology and evolution of the Magela Creek catchment in the monsoon tropics of northern Australia. Sediment. Geol. 83, 277-302 (1993).

74. Nanson, G. C. et al. Alluvial evidence for major climate and flow regime changes during the middle and late Quaternary in eastern central Australia. Geomorphology 101, 109-129 (2008).

75. Longmore, M. E. \& Heijnis, H. Aridity in Australia: Pleistocene records of palaeohydrological and palaeoecological change from the perched lake 
sediments of Fraser Island, Queensland, Australia. Quat. Int. 57, 35-47 (1999).

76. Prideaux, G. J. et al. Mammalian responses to Pleistocene climate change in southeastern Australia. Geology 35, 33-36 (2007).

77. Arnold, L. J., Duval, M., Falguères, C., Bahain, J.-J. \& Demuro, M. Portable gamma spectrometry with cerium-doped lanthanum bromide scintillators: suitability assessments for luminescence and electron spin resonance dating applications. Radiat. Meas. 47, 6-18 (2012).

78. Mejdahl, V. Thermoluminescence dating: beta-dose attenuation in quartz grains. Archaeometry 21, 61-72 (1979).

79. Brennan, B. Beta doses to spherical grains. Radiat. Meas. 37, 299-303 (2003).

80. Guérin, G., Mercier, N. \& Adamiec, G. Dose-rate conversion factors: update. Anc. TL 29, 5-8 (2011).

81. Prescott, J. R. \& Hutton, J. T. Cosmic ray contributions to dose rates for luminescence and ESR dating: large depths and long-term time variations. Radiat. Meas. 23, 497-500 (1994).

82. Aitken, M. J. Thermoluminescence Dating (1985).

83. Demuro, M., Arnold, L. J., Aranburu, A., Gomez-Olivencia, A. \& Arsuaga, J.L. Single-grain OSL dating of the Middle Palaeolithic site of Galería de las Estatuas, Atapuerca (Burgos, Spain). Quat. Geochronol. 49, 254-261 (2019).

84. Aitken, M. J. Introduction to Optical Dating: the Dating of Quaternary Sediments by the Use of Photon-stimulated Luminescence (Clarendon Press, 1998).

85. Murray, A. S. \& Wintle, A. G. Luminescence dating of quartz using an improved single-aliquot regenerative-dose protocol. Radiat. Meas. 32, 57-73 (2000).

86. Arnold, L. J. et al. OSL dating of individual quartz 'supergrains' from the Ancient Middle Palaeolithic site of Cuesta de la Bajada, Spain. Quat. Geochronol. 36, 78-101 (2016).

87. Demuro, M., Arnold, L. J., Parés, J. M. \& Sala, R. Extended-range luminescence chronologies suggest potentially complex bone accumulation histories at the Early-to-Middle Pleistocene palaeontological site of Huéscar-1 (Guadix-Baza basin, Spain). Quat. Int. 389, 191-212 (2015).

88. Méndez-Quintas, E. et al. First evidence of an extensive Acheulean large cutting tool accumulation in Europe from Porto Maior (Galicia, Spain). Sci. Rep. 8, 3082 (2018).

89. Pietsch, T. J. Optically stimulated luminescence dating of young $(<500$ years old) sediments: Testing estimates of burial dose. Quat. Geochronol. 4, 406-422 (2009).

90. Galbraith, R. \& Green, P. Estimating the component ages in a finite mixture. Int. J. Radiat. Appl. Instrum. Part D. Nucl. Tracks Radiat. Meas. 17, 197-206 (1990).

91. Galbraith, R. F., Roberts, R. G., Laslett, G. M., Yoshida, H. \& Olley, J. M. Optical dating of single and multiple grains of quartz from Jinmium rock shelter, northern Australia: Part I, experimental design and statistical models. Archaeometry 41, 339-364 (1999).

92. Arnold, L. J., Roberts, R. G., Galbraith, R. F. \& DeLong, S. A revised burial dose estimation procedure for optical dating of youngand modern-age sediments. Quat. Geochronol. 4, 306-325 (2009).

93. Price, G. J., Feng, Y.-x, Zhao, J.-x \& Webb, G. E. Direct U-Th dating of vertebrate fossils with minimum sampling destruction and application to museum specimens. Quat. Geochronol. 18, 1-8 (2013).

94. Zhou, H., Zhao, J., Qing, W., Feng, Y. \& Tang, J. Speleothem-derived Asian summer monsoon variations in Central China, 54-46 ka. J. Quat. Sci. 26, 781-790 (2011).

95. Woodroffe, C. D., Short, S. A., Stoddart, D. R., Spencer, T. \& Harmon, R. S. Stratigraphy and chronology of late Pleistocene reefs in the southern Cook Islands, south Pacific. Quat. Res. 35, 246-263 (1991).

96. Sambridge, M., Grün, R. \& Eggins, S. U-series dating of bone in an open system: the diffusion-adsorption-decay model. Quat. Geochronol. 9, 42-53 (2012).

97. Dosseto, A. \& Marwick, B. UThwigl-An R Package for Closed-and Opensystem Uranium-thorium Dating (2019).

98. Joannes-Boyau, R., Duval, M. \& Bodin, T. MCDoseE 2.0 A new Markov Chain Monte Carlo program for ESR dose response curve fitting and dose evaluation. Quat. Geochronol. 44, 13-22 (2018).

99. Van der Kaars, W. Palynology of eastern Indonesian marine piston-cores: a Late Quaternary vegetational and climatic record for Australasia. Palaeogeogr., Palaeoclimatol., Palaeoecol. 85, 239-302 (1991).

100. Moss, P. T. in Treatise on Geomorphology (eds Shroder, J.F., Switzer, A.D. \& Kennedy, D.M.) 315-325 (Academic Press, 2013).

101. Meltzer, D. J. \& Mead, J. I. in Environments and Extinctions: Man in Late Glacial North America (eds Mead, J. I. \& Meltzer, D. J.) 145-174 (University of Maine, 1985).

102. Becerra-Valdivia, L., Leal-Cervantes, R., Wood, R. \& Higham, T. Challenges in sample processing within radiocarbon dating and their impact in $14 \mathrm{C}$-datesas-data studies. J. Archaeological Sci. 113, 105043 (2020).
103. Gillespie, R. et al. Man and megafauna in Tasmania: closing the gap. Quat. Sci. Rev. 37, 38-47 (2012)

104. Prideaux, G. J. et al. Timing and dynamics of Late Pleistocene mammal extinctions in southwestern Australia. Proc. Natl Acad. Sci. USA 107, 22157-22162 (2010)

105. Miller, G. et al. Human predation contributed to the extinction of the Australian megafaunal bird Genyornis newtoni approximately $47 \mathrm{ka}$. Nat. Commun. 7, 10496 (2016)

106. Grellet-Tinner, G., Spooner, N. A. \& Worthy, T. H. Is the "Genyornis" egg of a mihirung or another extinct bird from the Australian dreamtime? Quat. Sci. Rev. 133, 147-164 (2016).

107. Westaway, M. C., Olley, J. \& Grün, R. At least 17,000 years of coexistence: modern humans and megafauna at the Willandra Lakes, South-Eastern Australia. Quat. Sci. Rev. 157, 206-211 (2017).

108. Price, G. J. Plio-Pleistocene climate and faunal change in central eastern Australia. Episodes 35, 160-165 (2012).

109. Gillespie, R. \& Brook, B. W. Is there a Pleistocene archaeological site at Cuddie Springs? Archaeol. Ocean. 41, 1-11 (2006)

110. Roberts, R. G. \& Brook, B. W. Turning back the clock on the extinction of megafauna in Australia. Quat. Sci. Rev.: Int. Multidiscip. Rev. Res. J. 29, 593-595 (2010).

111. Australia, G. in Bioregional Assessment Source Dataset (ed. Bioregional Assessment Programme) (Geoscience Australia, 2013).

112. Whiteway, T. in Geoscience Australia, Canberra (ed. Geoscience Australia) (2009).

113. Malhi, Y. et al. Megafauna and ecosystem function from the Pleistocene to the Anthropocene. Proc. Natl Acad. Sci. USA 113, 838-846 (2016)

114. Owen-Smith, N. Contrasts in the large herbivore faunas of the southern continents in the late Pleistocene and the ecological implications for human origins. J. Biogeogr. 40, 1215-1224 (2013).

115. Price, G. J. et al. Temporal overlap of humans and giant lizards (Varanidae Squamata) in Pleistocene Australia. Quat. Sci. Rev. 125, 98-105 (2015).

116. Peters, K. J. et al. FosSahul 2.0, an updated database for the Late Quaternary fossil records of Sahul. Sci. Data 6, 1-7 (2019).

\section{Acknowledgements}

We acknowledge and pay respect to the traditional owners past and present of the lands of the Barada Barna people and thank them for their guidance and contributions. We thank all QM Geosciences staff and volunteers for assistance with this project and in particular thank C. Chiotakis, N. Sands, P. Bishop, E. Cannon, K. Spring, J. Wilkinson, P. Tierney, J. Cramb, N. Newman, I. Mitchell, D. Kennedy, A. Hodgkinson, A. Hollingsworth, T. Clifford, D. Lewis, A. Rozefelds, E. Hatte, C. O'Bryen, Andrey Atuchin, Vlad Konstantinov and Capricorn Caves for their contributions and support. We thank the local land holders of the South Walker and Kemmis Creek areas for their hospitality, in particular the Baulch family. We thank L. Reed, A. Camens, S. Bourne, T. Ziegler, H. Janetzki, P. Couper, A. Amey and C. Janis for their contribution of comparative specimens and imagery. We thank all BHP and BHP Mitsui Coal South Walker Creek Mine staff past and present who have been involved with this project, in particular we thank J. Simpson, B. Clarke, R. Hailstone, J. Schumacher, S. Batten, M. Jones, J. McGill, J. Yanes, A. Cooke, A. Bull, C. Lavey, P. Jeston and V. O’Brien for their support. This project has been supported by the Queensland Museum Foundation, Queensland Museum, BHP, BHP Mitsui Coal and BMA. We thank I. Galloway, S. Miller, J. Thompson, J. Palmer, E. Muller, E. Stolberg J. Hooper, M. Anderson, R. Rew, D. Bunting, M. Partridge, R. Adlard A. Turley, and S. Baker for this. The OSL dating research undertaken by R.L. and L.J.A was supported by Australian research Council Future Fellowship grant FT130100195. Useries dating at UQ was supported by Australian Research Council grants DP0881279 and DP120101752 to G.J.P. J.L. is supported by ARC Future Fellowship grant FT160100450. Queensland Xray, St. Vincents Hospital, Princess Alexandra Hospital, Mater Hospital and Museums Victoria are thanked for provision of CT scan data.

\section{Author contributions}

S.A.H., R.A.L., R.L., L.J.A. and T.P. conceived the project, and S.A.H. and R.A.L. supervised the project. All authors contributed to the data interpretation, writing and editing of the paper and Supplementary Information. S.A.H., R.A.L. and J.L. collected the fossil samples. R.L., G.J.P., R.J-B., A.D., S.A.H. and R.A.L. took geochronology samples. S. A.H. and R.A.L. undertook the taxonomic identifications in Supplementary Notes 1-2. S. A.H. and R.A.L. provided the stratigraphic and sedimentological assessment in Supplementary Notes 3-4. R.L., L.J.A., T.P. and J.O. undertook the OSL geochronology analysis in Supplementary Note 5. R.W. undertook the radiocarbon analysis in Supplementary Note 6. G.J.P. undertook uranium-series analysis in Supplementary Note 7. R.J.-B. and A.D. undertook the uranium-series and ESR analysis in Supplementary Note 8. P.M. undertook the palynological assessment in Supplementary Note 9.

\section{Competing interests}

The authors declare no competing interests. 


\section{Additional information}

Supplementary information is available for this paper at https://doi.org/10.1038/s41467020-15785-w.

Correspondence and requests for materials should be addressed to S.A.H.

Peer review information Nature Communications thanks Matt Cupper and the other, anonymous, reviewers for their contribution to the peer review of this work. Peer reviewer reports are available.

Reprints and permission information is available at http://www.nature.com/reprints

Publisher's note Springer Nature remains neutral with regard to jurisdictional claims in published maps and institutional affiliations. (c) (i) Open Access This article is licensed under a Creative Commons Attribution 4.0 International License, which permits use, sharing, adaptation, distribution and reproduction in any medium or format, as long as you give appropriate credit to the original author(s) and the source, provide a link to the Creative Commons license, and indicate if changes were made. The images or other third party material in this article are included in the article's Creative Commons license, unless indicated otherwise in a credit line to the material. If material is not included in the article's Creative Commons license and your intended use is not permitted by statutory regulation or exceeds the permitted use, you will need to obtain permission directly from the copyright holder. To view a copy of this license, visit http://creativecommons.org/ licenses/by/4.0/.

(c) Crown 2020 